\title{
PYROLYZED PHOTORESIST FILM ELECTRODES FOR APPLICATION IN ELECTROANALYSIS
}

\author{
Vlastimil ґ̌eháček ${ }^{*}$ - Ivan Hotový ${ }^{*}$ - Marian Vojs * \\ — Mário Kotlár * Thomas Kups ${ }^{* *}$ _ Lothar Spiess ${ }^{* *}$
}

\begin{abstract}
Pyrolyzed photoresist film (PPF) electrodes for application in electroanalysis were prepared on alumina substrates. These electrodes were characterized for their electrical, microstructural (by Raman spectroscopy) and electrochemical properties. As a support, the PPF electrodes were tested for simultaneous determination of $\mathrm{Pb}$ (II), $\mathrm{Cd}$ (II) and $\mathrm{Zn}$ (II) in an aqueous solution on in-situ formed bismuth film by square wave voltammetry (SWV). The dependence of the stripping responses on the concentration of target metals was linear in the range from $1 \times 10^{-8}$ to $9 \times 10^{-8} \mathrm{~mol} / \mathrm{L}$. The effect of activation of the PPF surface by argon plasma on analytical performance of bismuth film electrode (BiFE) on PPF support was also investigated.

K e yw ords: pyrolyzed photoresist film, Bismuth film electrode, anodic stripping voltammetry
\end{abstract}

\section{INTRODUCTION}

General trends for environmentally friendly analytical methods and alternative materials have continuously been sought. From this point of view bismuth film electrodes are very promising in the field of electrochemical analysis. Bismuth has a potential to replace toxic mercury used most frequently for determination of heavy metals (such as $\mathrm{Cu}, \mathrm{Cd}, \mathrm{Pb}, \mathrm{Zn}$ ) by anodic stripping voltammetry (ASV) $[1,2]$. The attractive properties of bismuth films include simple preparation, high sensitivity, excellent peak resolution, insensitivity to dissolved oxygen in aqueous solutions, negligible toxicity and ability to operate in highly alkaline media [3-5]. Anodic stripping voltammetry is a very attractive electroanalytical technique for determination of trace heavy metals. The method is characterized by remarkable sensitivity and extremely low detection limits $(<\mathrm{ppb})$. Other advantages such as the ability to determine simultaneously several metals with high selectivity, rapidity, simplicity and low cost of the analyses are important. The high sensitivity and low detection limits are mainly given by the first step involving preconcentration of the analyte species in accumulating bismuth film, which is carried out under a fixed reduction potential for a predetermined time. In the second, stripping step, the accumulated species are stripped from bismuth into the solution by reoxidation. The stripping current peaks are proportional to the concentration of the species accumulated in bismuth and, hence, to the concentration in the analyte. Toxic metals can simultaneously be determined for concentration levels down to sub-ppb by pulse techniques such as differential pulse voltammetry (DPV) and mainly square wave voltammetry (SWV). The stripping analysis by SWV eliminates the time-consuming deaeration step because the stripping step is less sensitive to irreversible processes at high square wave frequency such as reduction of oxygen dissolved in aqueous solutions $[6,7]$. Thanks to this technique, the oxygen interference with analytical signal is strongly reduced. In general, the performance of anodic stripping voltammetry with accumulating metal film is strongly affected by the supporting electrode material. An ideal electrode should possess low ohmic resistance, chemical and electrochemical inertness, good mechanical properties, high hydrogen and oxygen overvoltage (wide potential window), low background current and ease of reproduction of the electrode surface. The choice of the electrode support that bismuth is deposited onto is crucial. Carbonaceous substrates such as glassy carbon [8$11]$, carbon paste $[8,12]$, carbon fibre $[3,13,14]$, impregnated graphite [8], pencil-lead [15], diamond-like carbon (DLC) $[16,17]$, boron-doped diamond (BDD) but also gold $[5,13]$, platinum $[5]$ and others $[4,5]$ have been reported for bismuth deposition. A pyrolyzed photoresist film of $\mathrm{sp}^{2}$-bonded carbon is an attractive alternative to other carbon electrodes for application in electroanalyses [18]. Generally, PPF films are highly electrically conductive materials $\left(\sim 5 \times 10^{-3} \Omega \mathrm{cm}\right)$ with microstructure much like that of glassy carbon. In addition, PPF films are low in surface oxygen $(\mathrm{O} / \mathrm{C}=\sim 2 \%)$, probably due to hydrogen termination during the pyrolysis, and therefore are slightly resistant to oxidation on air. The main benefit of PPF films is their very high smoothness and possibility to pattern the films before pyrolysis by photolithogra-

\footnotetext{
Department of Microelectronics, Slovak University of Technology, Ilkovičova 3, 81219 Bratislava, Slovakia, vlastimil.rehacek@stuba.sk; ** FG Werkstoffe der Elektrotechnik, Institut für Werkstofftechnik, TU Ilmeau, Postfach 100565, 98684 Ilmenau, Germany
} 


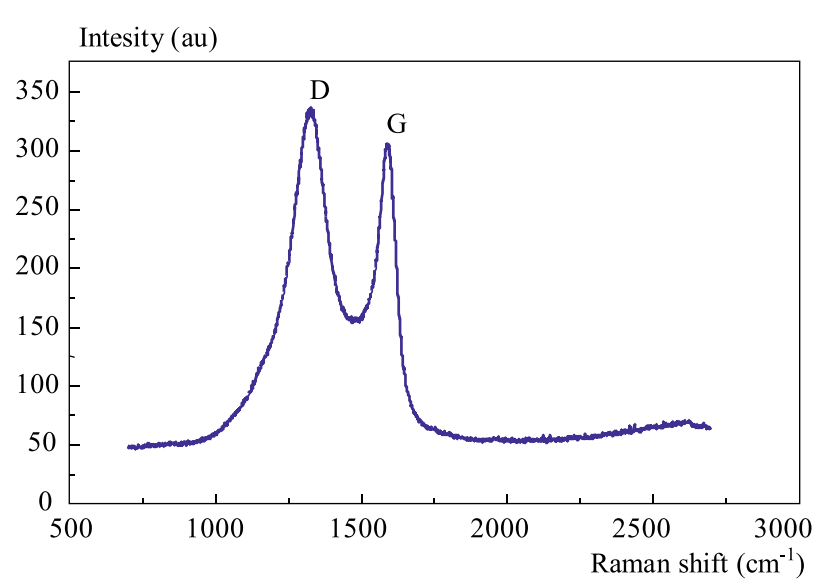

Fig. 1. Raman spectrum of pyrolyzed photoresist film

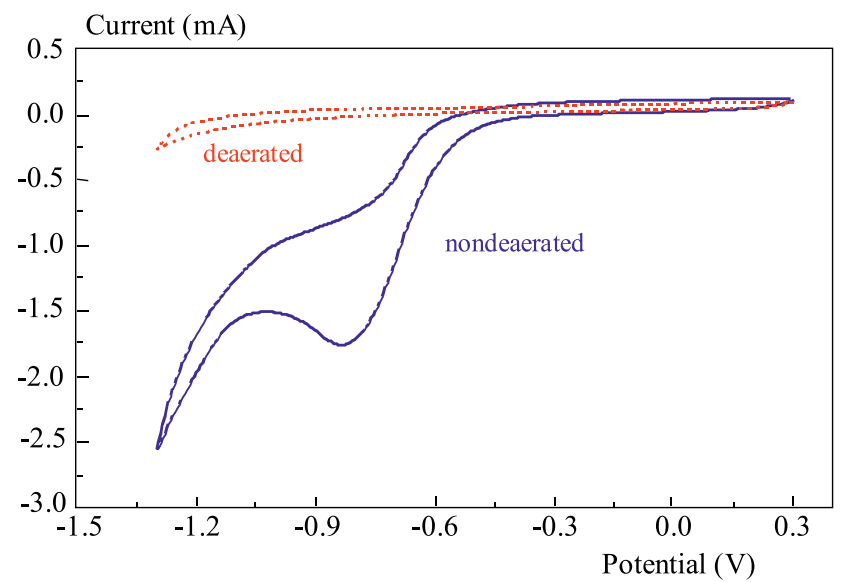

Fig. 2. Cyclic voltammograms of PPF electrode in nondeaerated and deareated $0.1 \mathrm{~mol} / \mathrm{L}$ acetate buffer solution $(\mathrm{pH} 4.5)$ at a scan rate of $50 \mathrm{mV} / \mathrm{s}$

phy. Moreover, their fabrication is inexpensive in comparison with glassy carbon. PPF is prepared by spin coating a thin layer of photoresist onto a clean substrate $(\mathrm{Si}$, $\mathrm{Al}_{2} \mathrm{O}_{3}$ ). The thickness of the photoresist layer (usually a few micrometers) is controlled by the spin speed and photoresist viscosity. After the coated substrate is softbaked at approximately $90-100{ }^{\circ} \mathrm{C}$ for $2 \mathrm{~min}$ on a hotplate, the substrate is placed in a quartz tube furnace for pyrolysis. The pyrolysis is usually conducted at $1000{ }^{\circ} \mathrm{C}$ for 1 hour under inert gas atmosphere (for example in forming gas). Of course, certain film shrinkage occurs, primarily in the film thickness, due to decomposition of the photoresist. In this work, pyrolyzed photoresist film electrodes as a support for bismuth film electroplating are characterized. Finally, the results of heavy metal determination by anodic stripping voltammetry with bismuth electrodes on PPF are presented.

\section{EXPERIMENTAL}

Pyrolyzed photoresist film electrodes were fabricated by spin coating a thin layer of photoresist S1813 SP15
(Shipley) at $3000 \mathrm{rpm}$ ( 1.4 $\mu \mathrm{m}$ in thickness $)$ on alumina substrates. The areas $\left(4 \times 4 \mathrm{~mm}^{2}\right)$ which act as working electrodes were defined photolithographically. Pyrolysis was carried out at $1000{ }^{\circ} \mathrm{C}$ for 1 hour under inert gas atmosphere $\left(95 \% \mathrm{Ar}+5 \% \mathrm{H}_{2}\right.$, at $200 \mathrm{sccm}$ flow $)$ in a quartz tube furnace $\left(20^{\circ} \mathrm{Cmin}^{-1}\right.$ of temperature ramp). After pyrolysis, the samples were cooled slowly to ambient temperature under constant flow inert gas. Before the PPF electrodes were used in electrochemical experiments, electrode pretreatment involving conditioning the surface morphology, microstructure and chemistry was performed. In general, pretreatment is used in order to obtain high-quality, reproducible measurements. This is because contaminants from the ambient air which are adsorbed onto the surface. Moreover, air oxidation as well as potential-induced oxidation of carbon materials in the electrolyte can produce changes in the surface chemistry. Therefore, every carbon electrode needs to be pretreated before its use. There are several procedures for carbon materials treatment [18]. Our standard pretreatment protocol for activation of PPF electrode involved solvent cleaning at first. Soaking the electrode in isopropanol for $30 \mathrm{~min}$ effectively dissolved contaminants from the surface without any microstructural damage. This procedure was applied once only after the electrode was prepared. Immediately before each measurement, the electrode was polarized by cycling ( 5 of cycles) in $0.1 \mathrm{~mol} / \mathrm{L}$ acetate buffer solution between -1.5 and $1.5 \mathrm{~V}$ at a scan rate of $50 \mathrm{mV} / \mathrm{s}$. All the stock solutions were prepared from analytical grade chemicals $\left(\mathrm{Bi}\left(\mathrm{NO}_{3}\right)_{3} \times 5 \mathrm{H}_{2} \mathrm{O}-99.999 \%, \mathrm{~Pb}\left(\mathrm{NO}_{3}\right)_{2}\right.$ $-99.0 \%, \mathrm{Cd}\left(\mathrm{NO}_{3}\right)_{2} \times 4 \mathrm{H}_{2} \mathrm{O}-99.0 \%, \mathrm{Zn}\left(\mathrm{NO}_{3}\right)_{2} \times$ $6 \mathrm{H}_{2} \mathrm{O}-99.0 \%, \mathrm{CH}_{3} \mathrm{COOH}-99.8 \%, \mathrm{CH}_{3} \mathrm{COONa}$ - $99.0 \%$ ) in $18 \mathrm{M} \Omega \mathrm{cm}$ deionised water. Voltammetric experiments were performed with an electrochemical sensor interface (PalmSens, Palm Instruments BV) in combination with a magnetic stirrer and personal computer. SWV was used in the measurement of the stripping voltammograms. A three-electrode arrangement was used in all experiments. As a reference, a home-made $\mathrm{Ag} / \mathrm{AgCl} / \operatorname{agar} \mathrm{Cl}(3 \mathrm{~mol} / \mathrm{L}) / \operatorname{agar} \mathrm{NO}_{3}^{-}(1 \mathrm{~mol} / \mathrm{L})$ electrode and, as a counter electrode, a platinum wire were used. Acetate buffer solution with concentration of $0.1 \mathrm{~mol} / \mathrm{L}$ $(\mathrm{pH}=4.5)$ was used in all electrochemical measurements. Electrochemical properties of PPF electrodes were investigated by cyclic voltammetry (CV). The morphology and microstructure of PPF films was investigated by SEM and Raman spectroscopy.

\section{RESULTS AND DISCUSSION}

\subsection{Characterization of pyrolyzed photoresist film}

Thin pyrolyzed photoresist film electrodes were first analyzed for their electrical properties. By a 4-point probes method we have found a sheet resistance of film of $44 \Omega / \square$. This electrode resistance can be more reduced if 


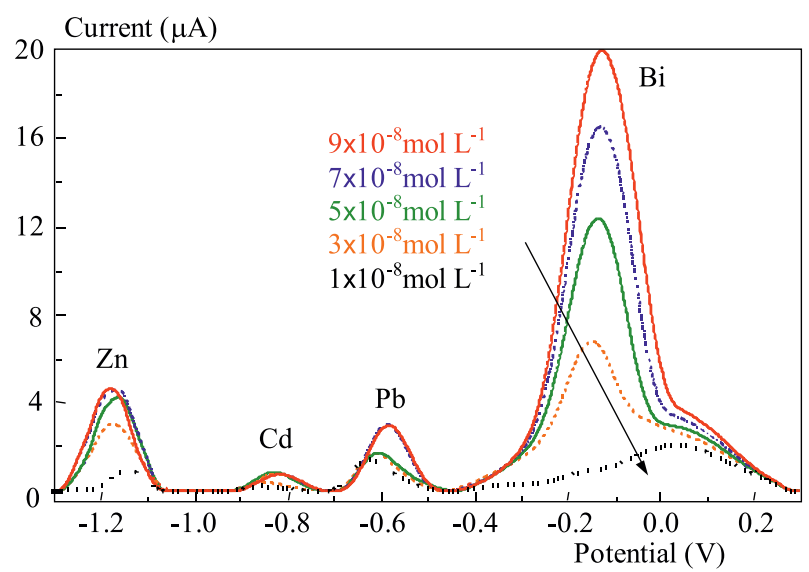

Fig. 3. Square wave stripping voltammograms $\left(E_{\text {step }}=25 \mathrm{mV}\right.$, $E_{\text {pulse }}=80 \mathrm{mV}$ and frequency $25 \mathrm{~Hz}$ ). Dependence of current response of $\mathrm{BiFE}$ on $\mathrm{PPF}$ on concentration of $\mathrm{Bi}(\mathrm{III})$ in $0.1 \mathrm{~mol} / \mathrm{L}$ acetate buffer ( $\mathrm{pH} 4.5)$; concentration of each of metals: $2 \times 10^{-8} \mathrm{~mol} / \mathrm{L}, 120 \mathrm{~s}$ preconcentration at $-1.3 \mathrm{~V}$

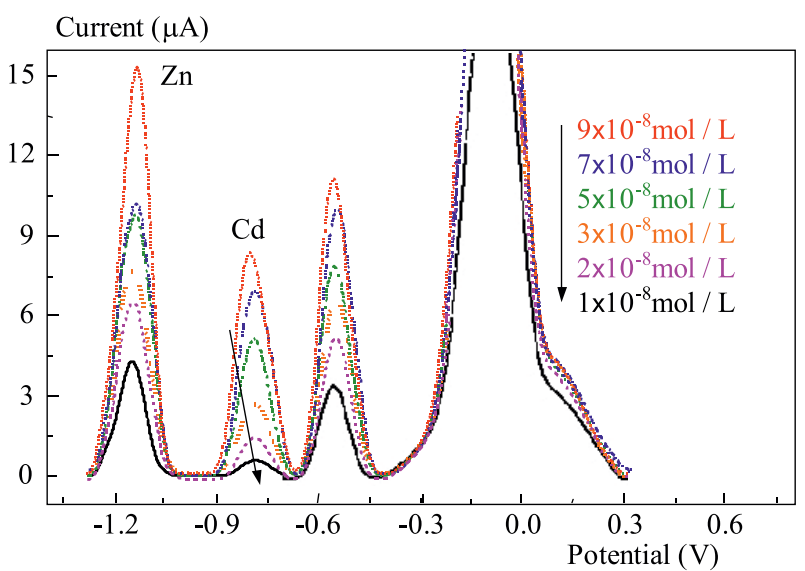

Fig. 4. Square wave stripping voltammograms $\left(E_{\text {step }}=25 \mathrm{mV}\right.$, $E_{\text {pulse }}=80 \mathrm{mV}$ and frequency $25 \mathrm{~Hz}$ ). Dependence of current response of $\mathrm{BiFE}$ on $\mathrm{PPF}$ on concentration of target metals in $0.1 \mathrm{~mol} / \mathrm{L}$ acetate buffer ( $\mathrm{pH} 4.5) ; \mathrm{Bi}(\mathrm{III})$ concentration $7 \times 10^{-7} \mathrm{~mol} / \mathrm{L}, 180 \mathrm{~s}$ preconcentration at $-1.3 \mathrm{~V}$

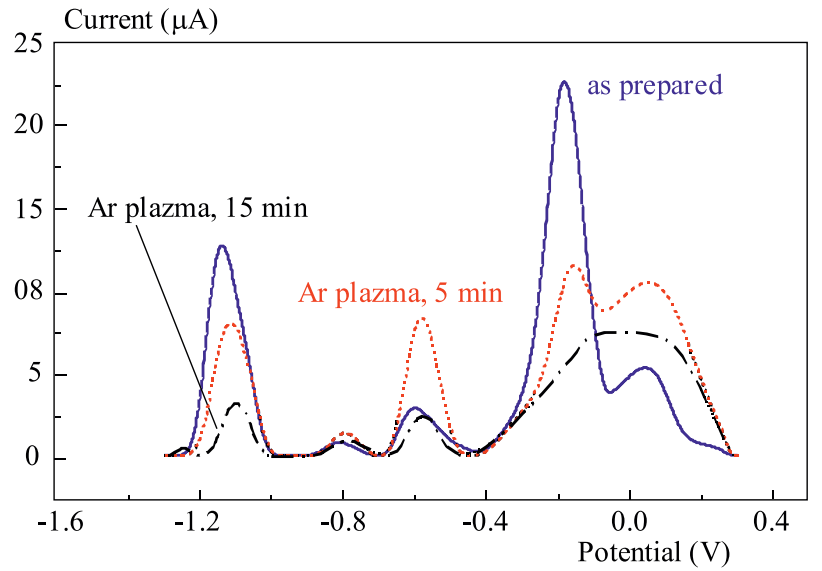

Fig. 5. Square wave stripping voltammograms $\left(E_{\text {step }}=25 \mathrm{mV}\right.$, $E_{\text {pulse }}=80 \mathrm{mV}$ and frequency $25 \mathrm{~Hz}$ ). Influence of activation of PPF surface by Ar plasma (162 mTorr at $100 \mathrm{sccm}$ of Ar and $100 \mathrm{~W}$ ) on current responses of BiFE; concentration of target metals $2 \times 10^{8} \mathrm{~mol} / \mathrm{L}$ of each and $\mathrm{Bi}(\mathrm{III}) 7 \times 10^{-7} \mathrm{~mol} / \mathrm{L}$ in $0.1 \mathrm{~mol} / \mathrm{L}$ acetate buffer $(\mathrm{pH} 4.5) ; 180 \mathrm{~s}$ preconcentration at $-1.3 \mathrm{~V}$

we coat a substrate by a thicker photoresist film and/or use a conductive sublayer before photoresist coating. For example, if we used as a support an alumina substrate with Pt layer, prepared by thick film technology, the sheet resistance was excellently reduced to $0.07 \Omega / \square$. A useful tool for characterizing the microstructure of carbon materials is, in general, Raman spectroscopy. Raman spectra for PPF reveal two characteristic bands at $\sim 1358$ ("D") band) and 1580 ("G" band) $\mathrm{cm}^{-1}$ with intensity ratio "D"/ "G" in the range of $1.2-1.5$ [18]. This ratio correlates with the extent of microstructural disorder. Similar spectra are reported also for glassy carbon material. In Fig. 1, a typical Raman spectra of our sample is shown. In our case the two bands are slightly shifted $\left(1326\right.$ and $\left.1589 \mathrm{~cm}^{-1}\right)$ but their positions can reflect tensile or compressive stress within the film. Also, the intensity ratio "D" / "G" of our PPF was found lower (1.1). It can be explained that the microstructure of the film is less disordered and that it contains more graphitic structure. Electrochemical behaviour of PPF electrode was characterized by cyclic voltammetry in $0.1 \mathrm{~mol} / \mathrm{L} \mathrm{ac}-$ etate buffer solution with $\mathrm{pH}$ value of 4.5 in a potential range from -1.3 to $0.3 \mathrm{~V}$ at a scan rate of $50 \mathrm{mV} / \mathrm{s}$. For analyses of metals by ASV a low background current is very important in a broad potential range so as to achieve the highest signal to noise ratio and, thereby, the highest sensitivity. In Fig. 2, the current differences obtained with the same PPF electrode in a solution before and after deaeration with nitrogen for $10 \mathrm{~min}$ are shown. In the case of nondeaerated solution, the currents are much higher due to the reduction reaction of oxygen in the solution. At approximately $-0.8 \mathrm{~V}$, a characteristic increase of the reduction current from this reaction was observed. A sharp increase of the current over a potential approximately $-1.1 \mathrm{~V}$ stems from hydrogen evolution. On the other hand, the electrode in the deaerated solution is characterized by a high hydrogen overvoltage and the current dependence is linear in the whole range from 0.3 to $\sim-1.3 \mathrm{~V}$.

\subsection{Analytical performance of BiFE on PPF}

The concentration of $\mathrm{Bi}(\mathrm{III})$ used for formation of the bismuth film on carbon electrodes is known to influence the height of the stripping peaks of the target metals $[8,11,15]$. Stripping voltammograms with the PPF electrode for the solution with $2 \times 10^{-8} \mathrm{~mol} / \mathrm{L}$ concentration of each of $\mathrm{Pb}(\mathrm{II}), \mathrm{Cd}(\mathrm{II})$ and $\mathrm{Zn}(\mathrm{II})$ in $0.1 \mathrm{~mol} / \mathrm{L}$ acetate buffer are shown in Fig. 3. They were recorded at different contents of $\mathrm{Bi}(\mathrm{III})$ from $1 \times 10^{-7}$ (bismuth-to-metals ratio of $5: 1$ ) to $9 \times 10^{-7} \mathrm{~mol} / \mathrm{L}$ (bismuth-to-metals ratio of $45: 1$ ). As the $\mathrm{Bi}(\mathrm{III})$ concentration increased, all the peaks increased in height up to a ratio of $\sim 35: 1$ and the current responses of all metals became independent of additional increasing of $\mathrm{Bi}(\mathrm{III})$. We suppose that the dependence of the stripping responses on $\mathrm{Bi}(\mathrm{III})$ concentration at lower bismuth-to-metals ratios $(<35)$ is probably influenced by the fact that under these conditions the surface of PPF electrode is not covered by bismuth 
completely. The ability of using the BiFE for simultaneous determination of $\mathrm{Pb}(\mathrm{II}), \mathrm{Cd}(\mathrm{II})$ and $\mathrm{Zn}(\mathrm{II})$ with optimized SWV parameters for these PPF electrodes is illustrated in Fig. 4. All the peaks are well resolved and increase linearly with the metal concentration in the range from $1 \times 10^{-8}$ to $9 \times 10^{-8} \mathrm{~mol} / \mathrm{L}$. The resulting calibration plots were used for estimating the detection limits. On the basis of criteria for calculation of the detection limit ( $\mathrm{Y}$ intercept $+3 \times \mathrm{SD}$ ) the detection limits were estimated as $1.8 \times 10^{-8} \mathrm{~mol} / \mathrm{L}$ for $\mathrm{Pb}(\mathrm{II}), 1.0 \times 10^{-8} \mathrm{~mol} / \mathrm{L}$ for $\mathrm{Cd}(\mathrm{II})$ and $1.0 \times 10^{-8} \mathrm{~mol} / \mathrm{L}$ for $\mathrm{Zn}(\mathrm{II})$. In addition to our standard pretreatment protocol we have also investigated the effect of argon plasma used for activation of the PPF surface upon the analytical performance of the PPF electrode. A short $5 \mathrm{~min}$ treatment in Ar plasma strongly affected the surface properties of the electrode and thereby its analytical performance in stripping analysis as can be seen in Fig. 5. In many cases we have observed an appearance of a double peak of bismuth in voltammograms, with the main peak at $-0.185 \mathrm{~V}$ and a very small one at $0.035 \mathrm{~V}$. The reason of this splitting seems to be related to stripping of bismuth from different sites of PPF surface. So it is evident from Raman spectrum that PPF has exposed not only the basal but also edge planes whose the reactivity to contaminants is higher than that of the basal plane sites. Probably, the increased carbon-oxygen functionality at the edge plane sites could decelerate the rate of electron transfer when bismuth is stripped from the surface of PPF. A longer exposure (15 min) of PPF to Ar plasma confirmed our presumption. Unfortunately, an attempt to improve the performance of PPF electrodes in stripping analysis of target metals by treatment in Ar plasma was not successful.

\section{CONCLUSION}

A pyrolyzed photoresist film of $\mathrm{sp}^{2}$-bonded carbon is an attractive alternative to other carbon electrodes for application in electroanalyses. The main benefit of PPF films is their very high smoothness and possibility to pattern the films before pyrolysis by photolithography. Moreover, their fabrication is not expensive. PPF electrodes prepared on alumina substrates were characterized for their electrical, microstructural and electrochemical properties. It was found that PPFs formed by pyrolysis of photoresist S-1813 SP 15 at $1000{ }^{\circ} \mathrm{C}$ for 1 hour were highly electrically conductive with a sheet resistance of $44 \Omega / \square$. Raman spectra showed two characteristic "D" and "G" bands for PPF with their intensity ratio 1.1 which is slightly lower than the value reported for this material. It can be explained that the microstructure of film is less disordered and contains more of the graphitic structure. Electrochemical behaviour of PPF electrodes was characterized by cyclic voltammetry in $0.1 \mathrm{~mol} / \mathrm{L}$ acetate buffer solution. The current dependence of PPF was linear in the whole range from 0.3 to $\sim-1.3 \mathrm{~V}$ in deaerated solution. As a support, the PPF electrodes were tested for simultaneous determination of $\mathrm{Pb}(\mathrm{II}), \mathrm{Cd}(\mathrm{II})$ and $\mathrm{Zn}(\mathrm{II})$ in an aqueous solution on in-situ formed bismuth film by square wave voltammetry. The dependence of the stripping responses on the concentration of target metals was linear in the range from $1 \times 10^{-8}$ to $9 \times 10^{-8} \mathrm{~mol} / \mathrm{L}$. Unfortunately, pretreatment of PPF surface by Ar plasma caused degradation of the analytical performance of bismuth film electrode (BiFE) on PPF support in stripping analysis of target metals.

\section{Acknowledgements}

The work was supported by the Scientific Grant Agency of the Ministry of Education of the Slovak Republic and Slovak Academy of Sciences, No. 1/0553/09, $1 / 0857 / 08$ by the Slovak Research and Development Agency under contract No. VVCE-0049-07, No. APVV0548-07, LPP-0094-09 and by PPP Programmes of DAAD No. D/08/07742.

\section{REFERENCES}

[1] FEENEY, R.-KOUNAVES, S. P,: Microfabricated Ultramicroelectrode Arrays: Developments, Advances, and Applications in Environmental Analysis, Electroanalysis 12 (2000), 677-684.

[2] XIE, X.-STUBEN, D.-BERNER, Z.-ALBERS, J.-HINTSCHE, R.-JENTZEN, E.: Development of an Ultramicroelectrode Arrays (UMEAs) Sensor for Trace Heavy Metal Measurement in Water, Sens. Actuators B 97 (2004), 168-173.

[3] Hutton, E. A.-Hocevar, S. B.-OGOREvC, B.: Ex Situ Preparation of Bismuth Film Microelectrode for Use in Electrochemical Stripping Microanalysis, Anal. Chim. Acta 537 (2005), 285-292.

[4] ECONOMOU, A. : Bismuth-Film Electrodes: Recent Developments and Potentionalities for Electroanalysis, Trends in Analytical Chemistry 24 (2005), 334-340.

[5] ŠVANCARA, I.-VYTŘAS, K.: Electroanalysis with Bismuth Electrodes (Elektroanalýza s bismutovými elektrodami), Chem. Listy 100 (2006), 90-113. (in Czech)

[6] TERCIER, M. L.-BUFFLE, J.: Development of an Ultramicroelectrode Arrays (UMEAs) Sensor for Trace Heavy Metal Measurement in Water, Electroanalysis 5 (1993), 187-200.

[7] BRETT, C. M. A.-LIMA, J. F. C.-GARCIA, B. Q. : SquareWave Anodic Stripping Voltammetry in Stationary and Flowing Solution: a Comparative Study, Analyst 119 (1994), 1229-1233.

[8] KeFAla, G.-ECONOMOU, A.-Voulgaropoulos, A. -SOFONIOU, M.: A Study of Bismuth-Film Electrodes for the Detection of Trace Metals by Anodic Stripping Voltammetry and their Application to the Determination of $\mathrm{Pb}$ and $\mathrm{Zn}$ in Tapwater and Human Hair, Talanta 61 (2003), 603-610.

[9] WANG, J.-LU, J.-KIRGOZ, U. A.-HOCEVAR, S. B.-OGOREVC, B. : Insight into the Anodic Stripping Voltammetric Behavior of Bismuth Film Electrodes, Anal. Chim. Acta 434 (2001), 29-34.

10] WANG, J.-KIRGOZ, U. A.-LU, J.: Stripping Voltammetry with the Electrode Material Acting as a "Built-in" Internal Standard, Electrochem. Comm. 3 (2001), 703-706.

11] Charalambous, A.-ECOnomou, A.: A Study on the Utility of Bismuth-Film Electrodes for the Determination of $\mathrm{In}(\mathrm{III})$ in the Presence of $\mathrm{Pb}(\mathrm{II})$ and $\mathrm{Cd}(\mathrm{II})$ by Square Wave Anodic Stripping Voltammetry, Anal. Chim. Acta 547 (2005), $53-58$. 
[12] BALDRIANOVA, L.-SVANCARA, I.-VLCEK, M.-ECONOMOU, A.-SOTIROPOULOS, S. : Effect of Bi(III) Concentration on the Stripping Voltammetric Response of in Situ Bismuth-Coated Carbon Paste and Gold Electrodes, Electrochim. Acta 52 (2006), 481-490.

[13] BALDRIANOVA, L.-SVANCARA, I.-ECONOMOU, A.SOTIROPOULOS, S.: Anodic Stripping Voltammetry at in Situ Bismuth Plated Carbon and Gold Microdisc Electrodes in Variable Electrolyte Content Unstirred Solutions, Anal. Chim. Acta 580 (2006), 24-31.

[14] WANG, J.-LU, J.-HOCEVAR, S. B.-FARIAS, P. A. M. : Bismuth-Coated Carbon Electrodes for Anodic Stripping Voltammetry, Anal. Chem. 72 (2000), 3218-3222.

[15] DEMETRIADES, D.-ECONOMOU, A.-VOULGAROPOULOS, A.: A Study of Pencil-Lead Bismuth-Film Electrodes for the Determination of Trace Metals by Anodic Stripping Voltammetry, Anal. Chim. Acta 519 (2004), 167-172.

[16] LIU, L. X.—LIU, E. : Nitrogenated Diamond-Like Carbon Films for Metal Tracing, Surface \& Coatings Technology 198 (2005), 189-193.

[17] BUTSUDA, T.-ANITA, V.-SAITO, N.-TAKAI, O.: Electrochemical Probe into DLC Thin Films, 17th International Symposium on Plasma Chemistry, August 7th - 12th, 2005, Toronto, Canada, pp. 65-66.

[18] ZOSKI, C. G.: Handbook of Electrochemistry, Elsevier B.V., 2007, pp. 111-153.

\section{Received 17 April 2010}

Vlastimil Řeháček received his MSc in Nuclear Chemistry from the Comenius University in Bratislava in 1982 and his $\mathrm{PhD}$ in Electronics from the Slovak University of Technology in 2005. He is a scientific worker in Department of microelectronics, FEIT STU. His current research interests include the development of voltammetric sensors, gas sensors and photolithography.
Ivan Hotový received his MSc in Electronics from the Slovak University of Technology in Bratislava in 1982 and his Ph.D. in Electronics from the Slovak University of Technology in 1993. He is a scientific worker and lecturer at Department of microelectronics, FEIT STU. His current research interests include the development of gas sensors, magnetron sputtering of metal oxide films and plasma etching of compound semiconductors.

Marian Vojs received his MSc in Electronics from the Slovak University of Technology in Bratislava in 2002 and his $\mathrm{PhD}$ in Electronics from the Slovak University of Technology in 2009. He is working from 2009 as researcher at Department of Microelectronics at STU. Main interests of his research include deposition of carbon layers, diamond like carbon structures and characterizing thin films morphology, electrical and electrochemical properties and Raman spectroscopy.

Mário Kotlár received his MSc in Microelectronics from the Slovak University of Technology in Bratislava in 2010. He is a PhD student in Department of microelectronics, FEI STU. His current research interests include preparation of carbon nanotubes and their use for sensoric structures.

Thomas Kups received his Diploma in 2001 in the Department of Physics and his $\mathrm{PhD}$ in 2006 in the Department of Physics and Astronomy from the Friedrich-Schiller-University Jena, Germany. Since 2006, he is a scientific researcher at the Technical University Ilmenau. His recent research focuses on the transmission electron microscopy investigations of IIINitrides, metal-oxides and SiC.

Lothar Spiess is a Professor at Department of Materials Technology, Technical University of Ilmenau. His interest is concern to material microanalysis and semiconductor processing. 